\title{
Monitoring of Outbreaks of Bacterial Cold Water Disease among Ayu in a River Where Asymptomatic Carriers of Flavobacterium psychrophilum Were Released
}

\author{
Akira Kumagai $^{1 *}$, Akatsuki Nawata ${ }^{2}$ and Yuichi Taniai ${ }^{2}$ \\ ${ }^{1}$ Miyagi Prefecture Fisheries Technology Institute, Miyagi 986-2135, Japan \\ ${ }^{2}$ Miyagi Prefecture Fisheries Technology Institute, Freshwater \\ Fisheries Experimental Station, Miyagi 981-3625, Japan
}

(Received May 7, 2010)

\begin{abstract}
Occurrences of bacterial cold-water disease (BCWD) caused by Flavobacterium psychrophilum were monitored among released and wild ayu Plecoglossus altivelis in Hirose River in 2006 and 2007 in order to clarify the infection source. When hatchery-reared juvenile ayu were examined immediately prior to release, F. psychrophilum was not isolated. However, when fish from the same lots were reared until maturation, the bacterium was isolated from ripe fish, indicating that the released juvenile ayu were carriers. In epizootiological investigations in Hirose River, outbreaks of BCWD occurred from June to August in both years, but the source of BCWD seemed to differ: released ayu in 2006 and wild ayu in 2007. Additionally, the disease occurred in released ayu by the pathogen carried by themselves in 2007. The disease subsided in August when water temperature exceeded $20^{\circ} \mathrm{C}$. Thereafter, the prevalence of F. psychrophilum in ripe fish in the river increased to above $90 \%$ between October and November in both years.
\end{abstract}

Key words: bacterial cold-water disease, Flavobacterium psychrophilum, Plecoglossus altivelis, ayu, infection source, BCWD, epizootiology

Flavobacterium psychrophilum is the causative agent of bacterial cold water disease (BCWD) (Holt et al., 1993), and rainbow trout fry syndrome (Bernardet and Kerouault, 1989). In Japan, outbreaks of BCWD have often occurred in coho salmon Oncorhynchus kisutch hatcheries since the mid 1980s (Wakabayashi et al., 1991). BCWD has also been reported in cultured ayu Plecoglossus altivelis in 1987 (Wakabayashi et al., 1994) and wild ayu in 1993 (lida and Mizokami, 1996). Ayu is a popular fish for angling in Japan and a large number of juvenile ayu reared in hatcheries or collected from Lake Biwa, local rivers and sea coasts are annually released for the enhancement of ayu stocks. BCWD has spread throughout Japan via the release of the juveniles carrying the pathogen and has caused serious damage to populations of ayu in many rivers since the mid 1990s (Inouye, 2000). The spread of BCWD was considered to be due to introducing $F$. psychrophilum-infected decoy fish which are live ayu used in an angling method called "Tomozuri" (Izumi et al., 2007; Arai et al., 2007).

Even when hatchery-reared ayu, which had been negative for F. psychrophilum on the pre-release

\footnotetext{
* Corresponding author

E-mail: kumagai-ak557@ @ pref.miyagi.jp
}

inspection with the cultivation method, were released or used as live decoy fish, outbreaks of BCWD have annually occurred in the released ayu in Hirose River, Miyagi Prefecture since 2002. Since there is no fish farm rearing ayu around the catchment area of Hirose River, the released and live decoy ayu would be responsible for the occurrences of the disease in the river, indicating that detection of $F$. psychrophilum from asymptomatic carriers is rather difficult. When clinically normal salmonid stocks are inspected and checked for some viral disease agents and Renibacterium salmoninarum, it is recommended that sexual products (sperm and ovarian fluid) should be taken for samples at the time of spawning (OIE, 2006). F. psychrophilum has been detected from the ovarian fluid of sexually mature salmonid fish (Holt et al., 1993) and from the surface of eggs and milt of ripe ayu (Kumagai et al., 2004). These reports suggest the possibility that we could clarify whether hatchery-reared ayu carry the bacterium or not by means of examining them at the mature stage.

In many cases, outbreaks of BCWD occur mainly in rivers where juveniles carrying the pathogen have been released. This suggests that the released carriers infect wild juvenile ayu migrating from the sea, and therefore epizootiological studies on the occurrence of BCWD in both released and wild ayu in rivers after 
release are important for control of the disease. However, occurrences of the disease and the prevalence of F. psychrophilum in rivers, where carriers of juvenile ayu were stocked, have not been monitored.

In the present study, we confirmed that hatcheryreared ayu, in which F. psychrophilum had not been detected on the pre-release inspection, were asymptomatic carriers by means of rearing and reexamining them at the mature stage. After releasing the asymptomatic carriers in Hirose River in 2006 and 2007, the occurrence of BCWD in the released and wild ayu were monitored in the river, and PCR-RFLP genotypes of isolates were analyzed.

\section{Materials and Methods}

\section{River investigated}

The investigations were performed in Hirose River in central part of Miyagi Prefecture, Japan, where ayuangling is popular (Fig. 1). Since there is a weir without an effective fish way at the point of $10 \mathrm{~km}$ from its river mouth, most of the wild ayu which migrate up from the river mouth between May and June could not move to the upper reach above the weir. Therefore, approximately 100,000 hatchery-reared ayu are annually released in the upper reach in late May to supplement the shortage of wild ayu. The open season for game fishing for ayu is during July and September in Hirose River.

\section{Sampling of hatchery-reared ayu}

Four lots of hatchery-reared juvenile ayu (lot number $\mathrm{A} 1, \mathrm{~A} 2, \mathrm{~B} 1$ and $\mathrm{B} 2$ ) reared in two commercial fish farms (farm $A$ and $B$ ) in Miyagi Prefecture, were used for the experiments in 2006 and 2007. A1, B1 and A2 were the only lots to be released in Hirose River in 2006 and 2007, respectively. B1 and B2 were the only lots to be used in the river as live decoys in 2006 and 2007 , respectively.

Prior to release of the 3 lots $(A 1, B 1$ and $A 2)$ into
Hirose River in mid May in 2006 and 2007, apparently normal live ayu of each lot $(n=300)$ were transported to Miyagi Prefecture Fisheries Technology Institute Freshwater Fisheries Experimental Station (MFTIFFES) from each of two fish farms. Soon after arrival at the laboratory, 62-75 fish were taken from each lot for examination of $F$. psychrophilum. Remaining fish were held separately in running water at $15^{\circ} \mathrm{C}$ in a $1,000 \mathrm{~L}$ tank, then they were reared for five months until maturation with commercial dry pellets. The rearing water was pumped up from a depth of $20 \mathrm{~m}$ under the ground, and disinfected by the UV germicidal lamp (SANITRON SS401, SEN LIGHTS Co.). Part of dead fish and all survived ripe fish were examined for F. psychrophilum. In August 2007, 60 apparently normal live ayu (mean body weight $=59 \mathrm{~g}$ ) of B2, which were kept for use as live decoys at a fish angling shop located near to Hirose River, were transported to MFTIFFES. Thirteen out of 60 fish were immediately examined for F. psychrophilum and then the remaining fish were reared in a $200 \mathrm{~L}$ tank until maturation in the same manner as mentioned above. Dead and ripe fish were examined for F. psychrophilum. For the control, hatchery-reared ayu (mean body weight $=10 \mathrm{~g}$ ) derived from spawners which had been kept without infection with $F$. psychrophilum, which were considered to be free from the bacterium, were introduced from Gunma Prefectural Fisheries Experimental Station in April 2006. Sixty fish were immediately examined for F. psychrophilum, and then 240 fish were similarly reared in a 1,000 $\mathrm{L}$ tank until maturation. Dead and ripe fish were examined for F. psychrophilum during the rearing period.

\section{Sampling of ayu in river}

Samples were collected at seven stations in Hirose River from May to November in 2006 and 2007. Wild and released ayu caught by casting net or angling were examined for F. psychrophilum and were distinguished by the number of scales above the lateral line according

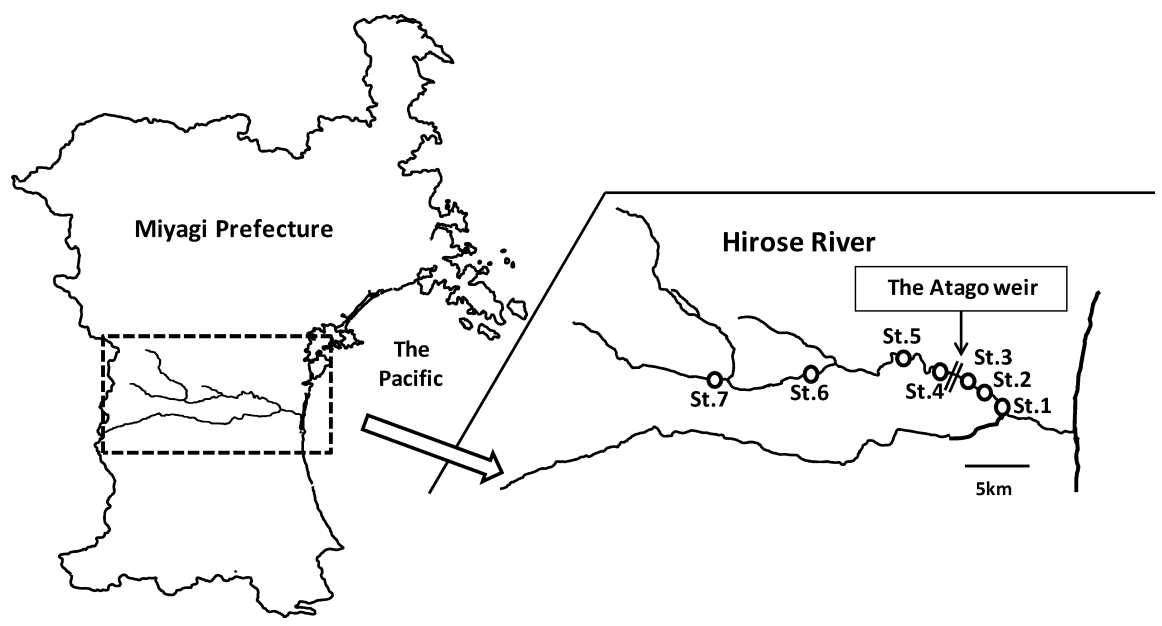

Fig. 1. Map showing the study sites in Hirose River, Miyagi Prefecture. 
to the method described by Toida (2001). The water temperature at St.3 (Fig. 1), which is monthly measured by Miyagi Prefectural Institute of Public Health and Environment, was used in the analysis.

Isolation of F. psychrophilum

After measuring the body weight and gonad weight, kidney, gill and skin lesion were taken with a cotton swab and streaked on an enriched Anacker and Ordal's agar plate (Lorenzen and Karas, 1992) with tobramycin at a concentration of $2.5 \mu \mathrm{g} / \mathrm{mL}$ (Kumagai et al., 2004) and then these plates were incubated at $15^{\circ} \mathrm{C}$ for 5 days. After incubation, presumptive identification of the isolated $F$. psychrophilum was made by indirect fluorescent antibody technique (IFAT) using an antiserum against F. psychrophilum FPC840, according to the method described by Kumagai et al. (1998). The antiserum was provided from the University of Tokyo. The IFAT positive strains for F. psychrophilum were definitively identified by PCR-RFLP (Izumi et al., 2003; Yoshiura et al., 2006). Tissues of gonad of ripe fish as well were examined during September and November. In Hirose River, the prevalence of F. psychrophilum in wild and released ayu was analyzed among each of two groups; one was ayu caught in the upper reach from the weir (St.4-7) and the other was ayu caught in the lower reach from it (St.1-3).

DNA extraction, PCR amplification and PCR-RFLP analysis

Total genomic DNA was prepared from isolates of F. psychrophilum using a chelating resin according to the method described by Izumi and Wakabayashi (1997). For the PCR analysis, PCR primer pair PSY-G1F, 5'-TGCAGGAAATCTTACACTCG-3' and PSY-G1R, 5'-GTTGCAATTACAATGTTGT-3' was used for the amplification of gyrB region (Izumi et al., 2003). PCR primer pair fpPPIC1F, 5'-GTACCATGATACAGTCAGGTTTTTATACCA-3' and fpPPIC1R, 5' -GCGTTTTTAAATCCAACTCTTGCTTCG-3' was used for the amplification of the PPIC gene region (Yoshiura et al., 2006). PCR amplification was performed in a total reaction volume of $20 \mu \mathrm{L}$. The reaction mixture contained $1 \mu \mathrm{L}$ of template DNA, $0.2 \mathrm{nmol}$ of each dNTP, 20 pmol of each primer and 1 unit of Taq DNA polymerase (Takara). Following PCR amplification, $5 \mu \mathrm{L}$ of PCR amplicon was checked by electrophoresis using a $1 \%$ agarose gel.

Restriction endonuclease Rsa I (Fermentas) and Hinf I (Fermentas) were used for digestion of PCR products of gyrB and PPIC DNA marker, respectively. The procedures of PCR amplification, enzyme digestion and agarose gel electrophoresis were performed according to the method described previously (Izumi et al., 2003; Yoshiura et al., 2006).

\section{Results}

Isolation of F. psychrophilum from hatchery-reared ayu

F. psychrophilum was not isolated from all four lots (A1, B1, A2 and B2) in the pre-release examination. When ayu were reared in tanks until maturation, cumulative mortality of each lot ranged from $63 \%$ to $99 \%$ and F. psychrophilum was isolated from dead fish in $\mathrm{A} 1$ $(9 / 59), B 1(10 / 32)$ and B2 (16/30) in August. From late September to October, the bacteria were also isolated from ripe fish in A1 (15/43), B1 (1/2), A2 (73/88) and B2 $(12 / 13)$. On the other hand, the bacteria were not isolated from dead and survived ripe fish in control group, although the cumulative mortality reached to $92 \%$. All isolates from $A 1$ and $B 1$ exhibited genotype $A / S$ and all isolates from $B 2$ exhibited genotype $A / R$, while those from A2 exhibited genotypes A/S and A/R (Table 1).

\section{Isolation of F. psychrophilum from ayu caught in Hirose} River

A total of 1191 ayu (1,063 wild ayu and 128 released ayu) and 1,787 ayu (1,475 wild ayu and 312 released ayu) were caught in Hirose River in 2006 and 2007, respectively.

In 2006, F. psychrophilum (genotype A/S) was first isolated from released fish with clinical signs of BCWD, which were caught in the upper reach in June. Thereafter, the bacteria of the same genotype were isolated from diseased released fish in July and from diseased wild fish between July and August, which were caught in the lower reach. The disease subsided by August when the water temperature exceeded $20^{\circ} \mathrm{C}$. Thereaf-

Table 1. Detection and genotype of $F$. psychrophilum isolates from hatchery-reared ayu

\begin{tabular}{|c|c|c|c|c|c|c|c|}
\hline \multirow[b]{2}{*}{ Year } & \multirow[b]{2}{*}{ Lot } & \multirow{2}{*}{$\begin{array}{l}\text { Pre-release examination } \\
\text { Apparently normal fish }\end{array}$} & \multicolumn{3}{|c|}{ Examination during rearing } & \multicolumn{2}{|c|}{ PCR-RFLP genotype } \\
\hline & & & $\begin{array}{l}\text { Cumulative } \\
\text { mortality (\%) }\end{array}$ & Dead fish & Survived ripe fish & No. of AR & No. of AS \\
\hline \multirow{3}{*}{2006} & A1 & $0 / 75^{* 1}$ & $81\left(182 / 225^{* 2}\right)$ & $9 / 59^{* 1}$ & $15 / 43^{* 1}$ & 0 & 24 \\
\hline & B1 & $0 / 63$ & $99(235 / 237)$ & $10 / 32$ & $1 / 2$ & 0 & 6 \\
\hline & Control & $0 / 60$ & $92(220 / 240)$ & $0 / 40$ & $0 / 20$ & & \\
\hline \multirow{2}{*}{2007} & $\mathrm{~A} 2$ & $0 / 62$ & $63(150 / 238)$ & $0 / 35$ & $73 / 88$ & 3 & 20 \\
\hline & B2 & $0 / 13$ & $72(34 / 47)$ & $16 / 30$ & $12 / 13$ & 20 & 0 \\
\hline
\end{tabular}

\footnotetext{
*1 Number of fish positive for $F$. psychrophilum / Number of fish examined

${ }^{* 2}$ Number of dead fish / Number of reared fish
} 
ter, the bacteria (genotypes A/S and A/R) were also isolated from ripe wild and released fish collected in the spawning ground in the lower reach in late September, and then the prevalence of $F$. psychrophilum in ripe fish increased above $90 \%$ between October and November, when the water temperature declined below $20^{\circ} \mathrm{C}$, and gonad-somatic index (GSI: gonad weight / body weight $\times 100)$ of male and female increased to $5 \%$ and $10 \%$, respectively (Fig. 2 and Table 2).
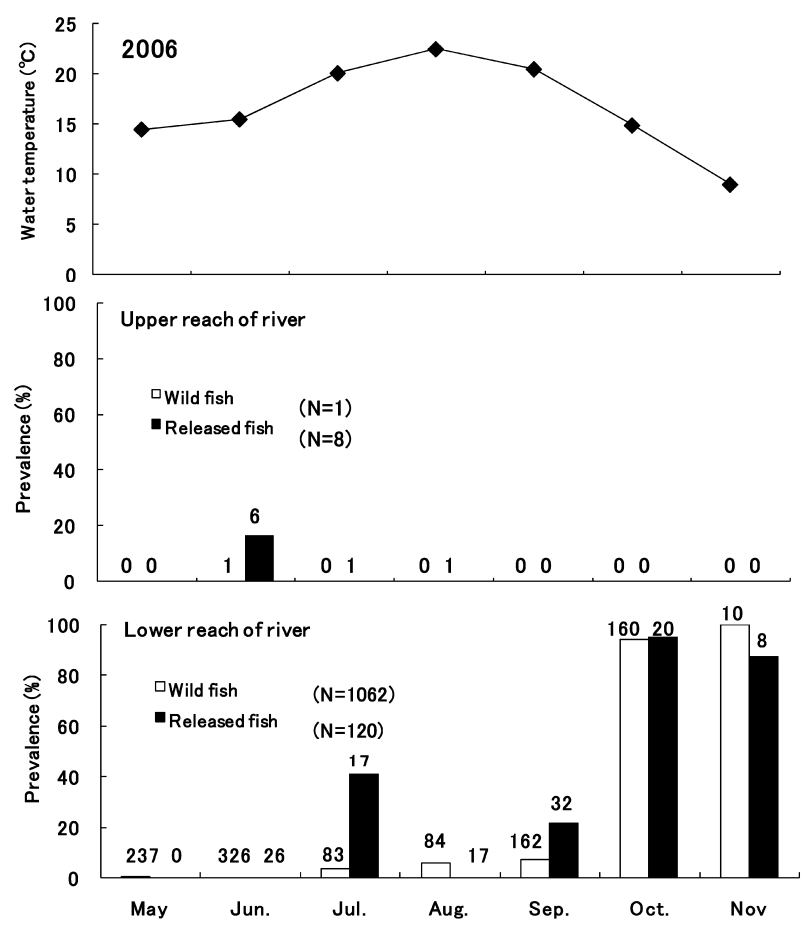

In June 2007, wild ayu with clinical signs of BCWD were collected in the lower reach and F. psychrophilum (genotype A/S) was isolated from those fish. In July, outbreaks of BCWD also occurred among released fish in the same area and the prevalence of $F$. psychrophilum (genotype A/S) increased to over $60 \%$. In the upper reach, BCWD outbreaks first occurred among released fish in August, and F. psychrophilum (genotypes A/S and $A / R$ ) was isolated from them. Thereafter, the
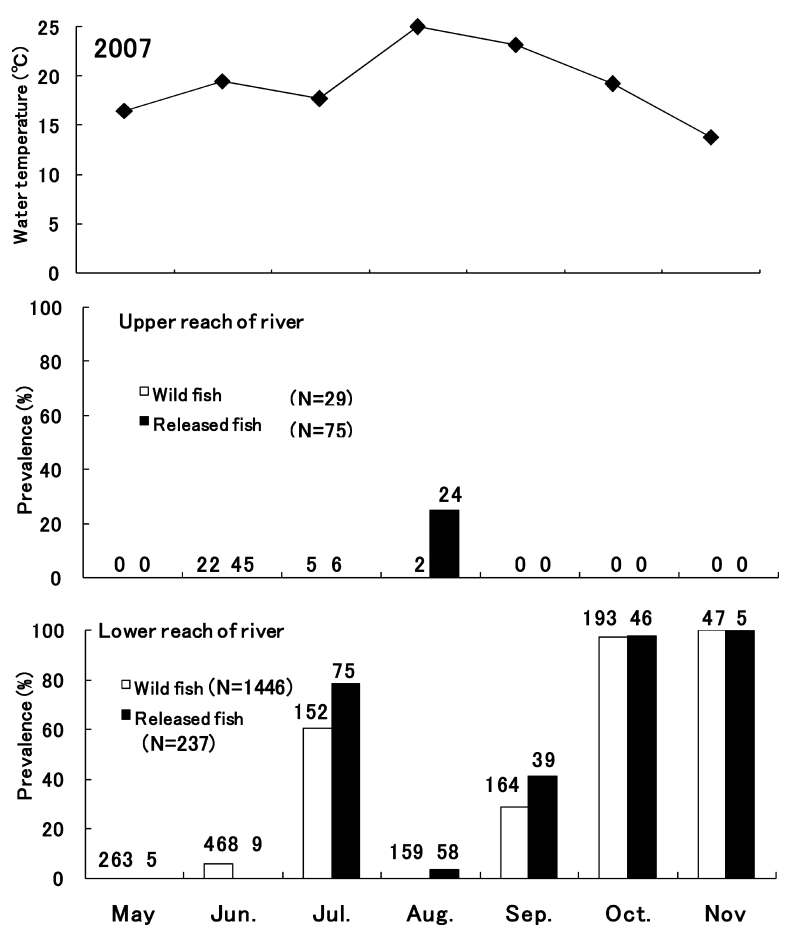

Fig. 2. Seasonal changes in the prevalence of Flavobacterium psychrophilum of ayu and water temperature in Hirose River in 2006 and 2007. The prevalence of F. psychrophilum was the total of kidney, gill, skin lesion and gonad. The number on the top of each column indicates the number of fish examined.

Table 2. Genotype of F. psychrophilum isolates from ayu in Hirose River in 2006 and 2007

\begin{tabular}{|c|c|c|c|c|c|c|c|}
\hline 2006 & & & & & & & \\
\hline & & May & Jun. & Jul. & Aug. & Sep. & Oct. \\
\hline \multirow{2}{*}{ Upper reach } & Wild ayu & & & & & & \\
\hline & Released ayu & & $\mathrm{A} / \mathrm{S}\left(1^{* 1}\right)$ & $\mathrm{A} / \mathrm{S}(7)$ & & & \\
\hline \multirow{2}{*}{ Lower reach } & Wild ayu & $\mathrm{B} / \mathrm{S}$ (2) & & & $\mathrm{A} / \mathrm{S}(6)$ & $\mathrm{A} / \mathrm{S}(11)$ & $\begin{array}{l}\mathrm{A} / \mathrm{S}(51) \\
\mathrm{A} / \mathrm{R}(7)\end{array}$ \\
\hline & Released ayu & & & & & $\begin{array}{l}\mathrm{A} / \mathrm{S}(7) \\
\mathrm{A} / \mathrm{R}(2)\end{array}$ & $\begin{array}{l}\mathrm{A} / \mathrm{S}(10) \\
\mathrm{A} / \mathrm{R}(3)\end{array}$ \\
\hline \multicolumn{8}{|l|}{2007} \\
\hline & & May & Jun. & Jul. & Aug. & Sep. & Oct. \\
\hline \multirow[b]{2}{*}{ Upper reach } & Wild ayu & & & & & & \\
\hline & Released ayu & & & & $\begin{array}{l}A / S(5) \\
A / R(1)\end{array}$ & & \\
\hline \multirow{2}{*}{ Lower reach } & Wild ayu & & $\mathrm{A} / \mathrm{S}(26)$ & $\mathrm{A} / \mathrm{S}(17)$ & & $\begin{array}{l}\mathrm{A} / \mathrm{S}(43) \\
\mathrm{A} / \mathrm{R}(3)\end{array}$ & $\begin{array}{l}\mathrm{A} / \mathrm{S}(52) \\
\mathrm{A} / \mathrm{R}(1)\end{array}$ \\
\hline & Released ayu & & & $\mathrm{A} / \mathrm{S}(13)$ & & $\begin{array}{l}\mathrm{A} / \mathrm{S}(14) \\
\mathrm{A} / \mathrm{R}(1)\end{array}$ & $\begin{array}{l}\mathrm{A} / \mathrm{S}(18) \\
\mathrm{A} / \mathrm{R}(3)\end{array}$ \\
\hline
\end{tabular}

*1 The number of isolates used is designated by numerals in parentheses. 
prevalence of F. psychrophilum (genotypes A/S and $A / R$ ) in wild and released fish caught in the lower reach increased from September and reached approximately 100\% between October and November (Fig. 2 and Table 2).

\section{Discussion}

Hatchery-reared ayu which were released or used as decoy fish in Hirose River were found to be asymptomatic carriers of F. psychrophilum (genotype A/S) in 2006, and those of the bacterium (genotype A/S and $A / R$ ) in 2007. The bacterium was not isolated from the hatchery-reared ayu examined during the initial prereleased examination without further rearing in both years. However, when the same lots were reared in a tank with pathogen-free water until maturation and examined, F. psychrophilum was isolated from the diseased and ripe fish. These results indicate that the bacterium, which hatchery-reared fish had carried asymptomatically at a level lower than the detection limit, multiplied in fish under stress by rearing or maturity and subsequently could be detected by the cultivation method.

Even when asymptomatic carriers were released in Hirose River in 2006 and 2007, source of BCWD outbreaks during June to August in 2006 and 2007 differed between stocks of ayu. In 2006, outbreaks of BCWD occurred first among the hatchery-reared ayu released in the upper reach and subsequently wild ayu were affected with BCWD in the lower reach one month after the disease occurrence in the upper reach. The genotype of isolates obtained from the infected wild fish was consistent with that of released hatchery-reared ayu. These results indicate that the outbreaks of BCWD in 2006 were caused by the pathogen being accompanied by the released fish. On the other hand, in 2007 the outbreaks of BCWD occurred first among wild fish in the lower reach in June, and then the released hatcheryreared ayu, which moved to the same area because of flood, were infected with BCWD in July. The isolates from wild and released ayu in the lower reach exhibited only genotype A/S, showing that source of BCWD occurrence in the lower reach was wild ayu. Because there was less rain than usual in 2007 , environmental conditions were not good for wild ayu which inhabit at a high density in the lower reach, causing the outbreaks of BCWD to occur earlier in the wild stock than in the released hatchery-reared ayu.

Between October and November, when the prevalence of $F$. psychrophilum in ripe ayu increased above $90 \%$ in Hirose River, the water temperature declined below $20^{\circ} \mathrm{C}$, and GSI of male and female increased to $5 \%$ and $10 \%$, respectively. Since the optimum temperature for growth of $F$. psychrophilum is around $15-20^{\circ} \mathrm{C}$ (Holt et al., 1993; Uddin and Wakabayashi,
1997), the multiple factors such as the multiplication of pathogen and immune-suppression due to maturation might increase the prevalence of bacteria in ayu.

The isolates from ripe wild ayu caught in Hirose River between September and November in 2006 exhibited genotype A/R as well, which was not detected from released hatchery-reared ayu in the same year, suggesting the possibility of transmission of F. psychrophilum from other fish species cohabiting with ayu or benthic diatoms, or via eggs of wild ayu other than the $F$. psychrophilum-infected ayu released into the river. In the present study, during October and November in 2006 and 2007, the prevalence of the bacterium in gonads of matured fish reached $38 \%$ (186/489), indicating that the surface of eggs spawned at a spawning ground was at least contaminated with the bacteria, even if intra-ovum infection does not occur in ayu eggs as described previously by Kumagai et al. (2004). Therefore, larvae that originated from surface-contaminating eggs could be infected with the bacteria in the process of hatching. Amita et al. (2000) reported that larvae of ayu collected in a river, where BCWD outbreaks occurred, were carriers of the bacteria. Because very few attempts have been made on bacteriological examination of larvae during their salt water phase, it is not clarified whether larvae carry the bacteria during their salt water phase or not. F. psychrophilum could not survive in $3 \%$ salinity water for 1 day (Madetoja et al., 2003). If the bacteria which juvenile ayu carried were inactivated during the salt water phase, the juveniles might be reinfected with the bacteria in the river, after they migrate from the sea. $F$. psychrophilum was detected from other fish species cohabiting with ayu and benthic diatoms, suggesting that these are potential winter reservoirs for F. psychrophilum infections in ayu (Amita et al., 2000; Izumi et al., 2005). On the other hand, if the larvae remain infected with the bacteria during their salt water phase, vertical transmission of F. psychrophilum would occur in wild ayu in rivers and the bacteria would be transmitted from spawner to offspring annually. Further research is needed to determine if vertical transmission of F. psychrophilum occurs in wild ayu.

In the present study, we could isolate $F$. psychrophilum from asymptomatic carriers by means of rearing and examining them during the maturation period, from which the bacterium had not directly been isolated prior to release. This method is useful to clarify whether hatchery-reared ayu, which have been already released into rivers, were asymptomatic carriers or not. Since it takes more than 4 months for the detection of $F$. psychrophilum, it is not suitable for a rapid diagnosis. Because we could demonstrate that the released hatchery-reared juvenile ayu carrying the pathogen infect the wild juvenile ayu in a river, it is important to clarify whether juveniles for release are free from the 
pathogen or not before being released, and subsequently pathogen-free juveniles should be released. For controlling the disease, further work to develop a rapid and reliable diagnostic method for asymptomatic carriers is needed. Furthermore, since epizootiological investigation on the prevalence of $F$. psychrophilum in ayu reveals that infection of the bacteria has already spread into wild ayu in Hirose River, it is essential to produce and release ayu having more resistance to BCWD.

\section{Acknowledgements}

We are indebted to Dr. Kinuko Ito (Graduate School of Agricultural Science Faculty of Agriculture, Tohoku University) for providing part of samples of ayu. We are grateful to the staff of Gunma Prefectural Fisheries Experimental Station for providing the experimental fish. This study was supported by grants from the Ministry of Agriculture, Forestry, and Fisheries of Japan and Miyagi Prefectural Government.

\section{References}

Amita, K., M. Hoshino, T. Honma and H. Wakabayashi (2000): An investigation on the distribution of Flavobacterium psychrophilum in the Umikawa River. Fish Pathol., 35, 193-197. (in Japanese with English abstract)

Arai, H., Y. Morita, S. Izumi, T. Katagiri and H. Kimura (2007): Molecular typing by pulsed-field gel electrophoresis of Flavobacterium psychrophilum isolates derived from Japanese fish. J. Fish Dis., 30, 345-355.

Bernardet, J. F. and B. Kerouault (1989): Phenotypic and genomic studies of 'Cytophaga psychrophila' isolated from diseased rainbow trout (Oncorhynchus mykiss) in France. Appl. Environ. Microbiol., 55, 1796-1800.

Holt, R. A., J. S. Rohovec and J. L. Fryer (1993): Bacterial coldwater disease. In "Bacterial diseases of fish" (ed. by V. Inglis, R. J. Roberts and N. R. Bromage). Blackwell Sci. Publ., London, pp. 3-22.

lida, Y. and A. Mizokami (1996): Outbreaks of coldwater disease in wild ayu and pale chub. Fish Pathol., 31, 157164.

Inouye, K. (2000): Coldwater disease in ayu (Plecoglossus altivelis). Aquabiology, 126, 35-38. (in Japanese)

Izumi, S. and H. Wakabayashi (1997): Use of PCR to detected Cytophaga psychrophila from apparently healthy juvenile ayu and coho salmon eggs. Fish Pathol., 32, 169-173.
Izumi, S., F. Aranishi and H. Wakabayashi (2003): Genotyping of Flavobacterium psychrophilum using PCR-RFLP analysis. Dis. Aquat. Org., 56, 207-214.

Izumi, S., H. Fujii and F. Aranishi (2005): Detection and identificaton of Flavobacterium psychrophilum from gill washings and benthic diatoms by PCR-based sequencing analysis. J. Fish Dis., 28, 559-564.

Izumi, S., S. Ouchi, T. Kuge, H. Arai, T. Mito, H. Fujii, F. Aranishi and A. Shimizu (2007): PCR-RFLP Genotypes associated with quinolone resistance in isolates of Flavobacterium psychrophilum. J. Fish Dis., 30, 141147.

Kumagai, A., K. Takahashi, S. Yamaoka and H. Wakabayashi (1998): Ineffectiveness of iodophore treatment in disinfecting salmonid eggs carrying Cytophaga psychrophila. Fish Pathol., 33, 123-128.

Kumagai, A., C. Nakayasu and N. Oseko (2004): Effect of tobramycin supplementation to medium on isolation of Flavobacterium psychrophilum from ayu Plecoglossus altivelis. Fish Pathol., 39, 75-78.

Kumagai, A., C. Nakayasu and N. Oseko (2004): No evidence for the presence of Flavobacterium psychrophilum within ayu eggs. Fish Pathol., 39, 183-187.

Lorenzen, E. and N. Karas (1992): Detection of Flexibacter psychrophilus by immunofluorescence in fish suffering from fry mortality syndrome: a rapid diagnostic method. Dis. Aquat. Org., 13, 231-234.

Madetoja, J., S. Nystedt and T. Wiklund (2003): Survival and virulence of Flavobacterium psychrophilum in water microcosms. FEMS. Microb. Ecol., 43, 217-223.

OIE (2006): Manual of Diagnostic Tests for Aquatic Animals Fifth Edition. Office International des Epizooties, Paris, France.

Toida, S. (2001): Method of distinction between wild and hatchery-reared ayu based on the number of scales above the lateral line. Zenkokukosyokasen ayushigenkenkyubukai hokokusyo, pp. 46-47. (in Japanese)

Uddin, M. N. and H. Wakabayashi (1997): Effects of temperature on growth and protease production of Cytophaga psychrophila. Fish Pathol., 32, 225-226.

Wakabayashi, H., M. Horiuchi, T. Bunya and G. Hoshiai (1991): Outbreaks of cold-water disease in coho salmon in Japan. Fish Pathol., 26, 211-212.

Wakabayashi, H., T. Toyama and T. lida (1994): A study on serotyping of Cytophaga psychrophila isolated from fishes in Japan. Fish Pathol., 29, 101-104.

Yoshiura, Y., T. Kamaishi, C. Nakayasu and M. Ototake (2006): Detection and genotyping of Flavobacterium psychrophilum by PCR targeted peptidyl-prolyl cis-trans isomerase C gene. Fish Pathol., 41, 67-71. (in Japanese with English abstract) 